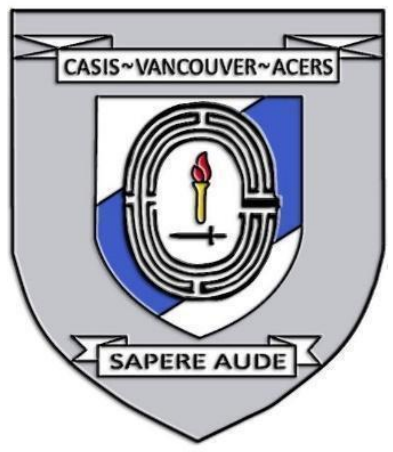

\title{
SOFT VIOLENCE, SOCIAL RADICALISATION, AND VIOLENT TRANSNATIONAL SOCIAL MOVEMENTS (VTSMS)
}

Date: November 25, 2020

Disclaimer: This briefing note contains the encapsulation of views presented by the speaker and does not exclusively represent the views of the Canadian Association for Security and Intelligence Studies.

\section{KEY EVENTS}

On November 25, 2020, Candyce Kelshall presented on the topic of Soft Violence, Social Radicalisation, and Violent Transnational Social Movements (VTSMs), at the 2020 CASIS West Coast Security Conference. Primary discussion topics included the distinction between terrorists and violent extremists, weapons used by violent extremists, social radicalisation and self actualisation (SRSA), the production of lone actors, and the intersectionality of violent extremist actors. This presentation was followed by a group panel for questions and answers, whereby conference attendees were provided with an opportunity to engage in discussion with Professor Kelshall and the other presenters.

\section{NATURE OF DISCUSSION}

\section{Presentation}

The presentation provided an overview of soft violence, VTSMs, violent extremists and how they differ from terrorists, as well as how cultural characteristics of violent extremist movements are distinctly different than those of terrorist organizations. The discussion progressed to understanding the weapons used by violent extremists and their increased potential for negative impacts on structural, judicial, and social systems, and the increased cause for concern violent extremists pose as compared to the weapons used by terrorists. The SRSAs of violent extremists and the predictability of the social radicalisation process of "lone actors" was also talked about. Finally, the concept of violent extremist actors holding extremist beliefs across multiple perspectives or "segments" was discussed in depth. 


\section{Question Period}

During the question period, it was discussed who fits within the VTSM theory. Furthermore, the speaker emphasized the importance of expanding our understanding of violence as currently, social/soft violence, which is non-kinetic, is often overlooked when examining the actions of VTSMs and extremist groups or actors. The importance of focusing future research on extremist symbology and its impact on social movements was also discussed, particularly in the context of Generation Z (born between 1993-2012) emerging as key content creators, distributors, and influencers/amplifiers for various social movements and VTSMs.

\section{BACKGROUND}

\section{Presentation}

Professor Kelshall began her presentation by making the distinction between terrorists and violent extremists as well as social movements (SMs) and violent transnational social movements (VTSMS). Terrorists act on a specific issue, which is political in intent and use violence to further their objectives. They amplify their cause by kinetic acts, not by the weight of association with others, and they justify these kinetic acts with ideologies. On the other hand, violent extremists often have multiple identity beliefs (not single specific issues) that manifest through soft and kinetic violence to impose dominance, legitimacy, authority, and supremacy over other identity groups. They often use social movements to amplify their perceived grievances in order to spread soft violence as widely and publicly as possible. VTSMs use the weight of association to provide legitimacy and justification of the movement and their violence, which does not have to be physical or kinetic, but can be soft or social violence. Nevertheless, they are identity-based, and violence forms part of that identity.

Both VTSMs and SMs are polycentric, reticulate, segmentary in nature - meaning they do not have a centralised leadership or command structure; they are networked and can have many different issues simultaneously expressed, making the movement seem disorganized or disjointed while also making them adaptable and resilient.

The key differences between SMs and VTSMs are that SMs are not violent and identity inclusive, unlike VTSMs, which are identity exclusive and use soft and kinetic violence as a primary tool for action. Social movements are primarily inclusive, seeking structural equality in the presence of perceived institutionally administered disparities, using activism - not violence - as their primary tool to bring about change. The identity exclusive nature of VTSMs makes them seek 
the preservation and maintenance of dominance, legitimacy, authority, and superiority of one identity group over another. They seek out other violent identity-based extremists for legitimacy and use violence to preserve and protect perceived positions of structural power.

However, violence does not have to be kinetic in nature. Soft violence are actions that fall short of criminally identifiable physical violence but that it is still considered violence. They can be seen as tactics and methods which are used to damage the fabric of society by impacting social cohesion. These actions are designed to entrench or highlight superiority of one group over another without necessarily having a physical or kinetic impact. For VTSMs soft violence is the main tool or weapon for communication, recruitment, radicalization, and the furtherance of identity-based violence.

It is also important to consider how violent extremists become radicalised, as the social, online and networked elements of SRSA's are arguably distinct from more traditional understandings of the radicalisation process. Within social radicalisation, violent extremist actors express their identity in their daily lives by joining communities with others who are like minded, leading to radicalisation through the normalisation of extremist sentiment. The normalisation of extremist sentiments, which occurs with online social radicalisation, further demonstrates how this process does not need to occur in person, but can occur in online communities. Professor Kelshall highlighted that although most of the extremist actors mapped out in the presentation had never met, there is evidence to suggest that they were consuming the same material and might have been influencing each other within online communities, which demonstrates the networked nature of social radicalisation. Networked radicalisation primarily depends on social network theory and group dynamics where individuals develop and become radicalised individually in insolation online. This isolation does not necessarily impact the social connection these individuals have in their communities, online constituencies, and atomic communities. All these elements contribute to violent extremists' process of social radicalisation and a sense of identity and belonging which in turn leads to self actualisation.

Professor Kelshall outlined the importance of understanding atomic communities which are not determined by where we live, but by who we identify with. Atomic communities allow us to disprove the fallacy of the "lone actor" as violent actors arguably emerge from these communities, both online and in the real world. By mapping the 'new geo-spactial contours' of these communities, it becomes clear that these online spaces must be patrolled in order to be proactive with regards to counter extremism. It is important to note that counter extremism and extremism 
begin with the literature, canon, and doctrine that these actors read, share, and incorporate into their beliefs and identities. Extremists rarely, if ever, communicate directly, but will often reference one another in manifestos and the like. Understanding these atomic communities, aids in understanding that there is a correlation between online sentiment and kinetic action.

Soft violence and toxicity have been seen to mirror kinetic action in the real world and can have major implications when we do not engage in the online sphere. The compression of extremist sentiments leads to legitimacy, which leads to justification, engagement, and action until we arrive at the weaponization of words and memes which are ultimately compressed through echo chambers into action. How does our silence allow for the normalization of extremist sentiments and language? What happens should the silence remain?

As demonstrated by Moghaddam's staircase to violence, traditional understandings of radicalisation suggest that as you move up the staircase of traditional radicalisation, there are fewer alternatives to an individual acting in a kinetically violent manner. However, Professor Kelshall adds to Moghaddam's work by pointing out that as one can go up the staircase, you can also approach it by going down the staircase, as seen in figure 1. As you go down, there are fewer alternatives to soft violence which begin to be felt by the general population, arguably due to the normalisation of extremist sentiment and rhetoric in the general population. This is demonstrated in the Nabla Model (figure 2), which demonstrates how people with poor metacognition might begin the journey to becoming violent extremist actors, and how supporters and sympathizers contribute to this compression of extremist sentiments.

Professor Kelshall's presentation continued to emphasize the extremely segmentary nature of violent extremism and violent extremist actors. Furthermore, she examined 40 violent actors who committed kinetic attacks between 2011 and 2020 and found that within this set of VTSM driven actors, 16 segments or strands of the VTSM doctrine emerged. The strength with which these violent actors identified with these segments were evaluated on a scale of 1-5 ranging from stating a grievance to committing kinetic actions consistent with a cause. This analysis suggests that all of the 40 violent extremist actors examined held strong extremist beliefs across multiple segments, which might further suggest that the more segments an actor crosses the more likely they are to conduct a violent kinetic act. 


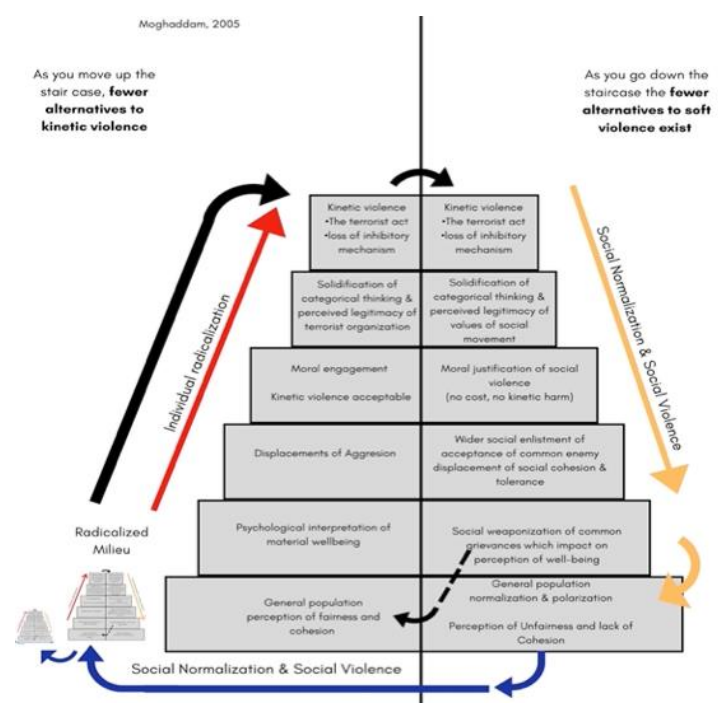

Figure 1. Staircase to social radicalisation

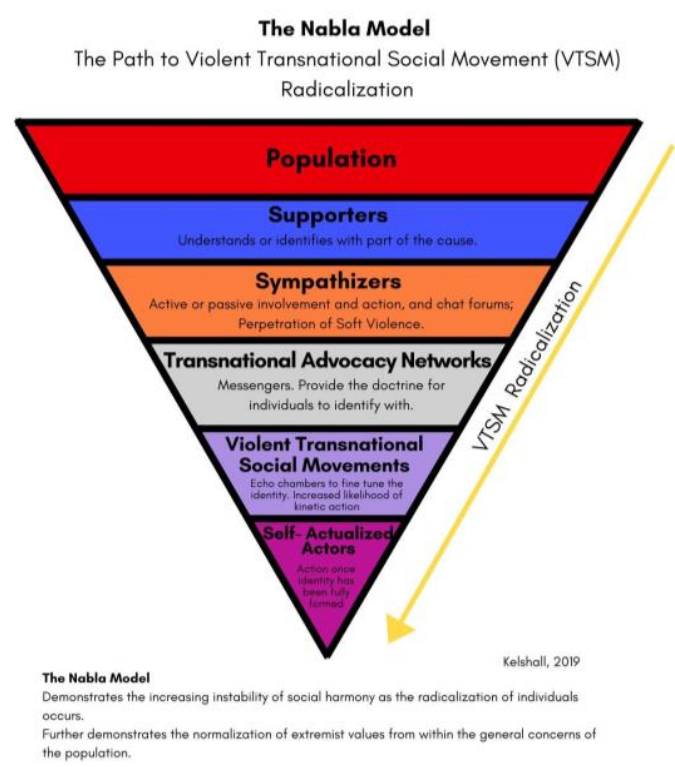

Figure 2. Nabla Model

The culmination of Professor Kelshall's presentation focused on the strong distinctions in organizational cultures and structures of violent extremists, terrorists, gangs, and international organized crime syndicates. Professor Kelshall further emphasized that the normalisation of extremist beliefs are arguably enhanced by family and cultural events planned and hosted by VTSMs. Overall, this suggests that violent extremism does not happen in a vacuum or 
with lone actors, but that socially radicalised, self actualised, violent actors emerge from a social environment of echo chambers where these actions are seen as acceptable. Addressing the environment created by soft violence is one of the first steps Professor Kelshall outlined as an area to address to proactively prevent the spread of violent extremist rhetoric and doctrine.

\section{Question Period}

In this section, it was discussed that if individuals are not violent, they do not fit into the VTSM theory. Professor Kelshall and participants discussed how violence can be both soft - such as the use of memes to normalize extremist language and sentiments - or kinetic - whereby a self-actualised actor has fully formed their identity and takes violent actions. Extremist symbology was also discussed as the spread of rhetoric and sentiments are increasingly spreading through memes, videos, and other content, which can include more imagery than text.

Participants also discussed the role of Generation Z (1993-2012) as 'digital natives' which have emerged as content creators and distributors, who can facilitate the societal normalization of sentiments - extremist and inclusive - and can be amplified through echo chambers which might compress this extremist sentiment into action.

\section{KEY POINTS OF DISCUSSION}

\section{Presentation}

- VTSMs are distinct from terrorists and other violent non-state criminal actors as they operate with the intention of imposing legitimacy, dominance, authority, and supremacy over other identity groups.

- Soft violence is a VTSMs tool used to damage the fabric of society by impacting social cohesion and may be more harmful than physical violence as it entrenches superiority over another group without having a kinetic impact.

- Terrorists act on a specific issue that is political in intent and amplify their cause by a kinetic act, and in turn, justify this act with ideology. Whereas violent extremists have multiple causes and are identity-based, using social movements to amplify their causes, and ultimately, making violence a part of that identity.

- Whereby terrorists are goal oriented, disciplined, invisible and have a clear structure of commerce and use violence strategically for spectacles, VTSMs are polycentric, networked nodes of influence that use violence (soft or 
kinetic) to project identity dominance and have a strong social media presence to create communities to strengthen tribal bonds.

- Social radicalisation is possible due to a societal normalisation of extremist language and sentiment. Self actualisation occurs when a fully radicalised identity has been formed.

- Violent extremist actors are extremist across multiple perspectives or segments, and the more segments an actor crosses in their language through soft violence, the more likely they are to conduct a violent or kinetic act.

- Violent transnational social movements produce lone actors through echo chambers that compress extremist sentiment into violent action.

\section{Question Period}

- If an individual is not violent (soft or kinetic), they do not fit within the VTSM theory.

- Expanding our understanding of violence is imperative as currently, social/soft violence, which is non-kinetic, is often overlooked when examining the actions of VTSMs and extremist groups or actors.

- Extremist symbology arguably contributes to the proliferation of rhetoric and sentiments that are increasingly spread through content, which can include more imagery than text.

- Generation Z (1993-2012) actors are emerging as content creators and distributors who facilitate the societal normalisation of sentiments, both extremist and inclusive. These sentiments are amplified through echo chambers that might compress this extremist sentiment into action.

\section{(c) (†) $\ominus$}

COY NO This work is licensed under a Creative Commons AttributionNonCommercial-NoDerivatives 4.0 International License.

(C) (Candyce Kelshall, 2021)

Published by the Journal of Intelligence, Conflict and Warfare and Simon Fraser University

Available from: https://jicw.org/ 